\title{
TEMAS HOMÉRICOS EN LA PINTURA ESPAÑOLA DEL SIGLO XIX *
}

\author{
POR \\ ENRIQUE ARIAS ANGLÉS \\ CSIC \\ AURORA GIL SERRANO \\ Profesora de Instituto
}

\begin{abstract}
En este estudio se recogen y analizan una serie de temas de la pintura española del siglo xIX referentes a los dos poemas homéricos de la Ilíada y la Odisea, fijando además concretamente los textos literarios de donde fueron extraídos y cotejando con ellos las composiciones pictóricas que pretendieron ilustrarlos, en caso de sernos conocidas, y cuando no nos lo son, tratando de poner las imágenes a través de dichos textos si nos lo permiten los títulos de las obras.

Palabras clave: Temas Homéricos. Pintura. Española. XIX.

A series of themes from nineteenth-century Spanish painting referring to Homer's The Iliad and The Odyssey are brought together and analyzed. Pictorial compositions are confronted with the specific texts that they supposedly illustrate, if identifiable. When they are not, then an attempt is made to relate texts to images, if the titles of the works allow.

Key words: Homeric themes. Painting. Spanish. Nineteenth century.
\end{abstract}

Los asuntos homéricos fueron unos de los motivos pictóricos, si no de los más abundantes sí muy representativos sin embargo, de esa corriente internacional hacia el ideal arcaizante latente en la pintura europea contemporánea de David, cuyo precedente más inmediato lo encontramos en Inglaterra, donde el descubrimiento de lo primitivo se había manifestado por primera vez en la línea abstracta de los dibujos de Flaxman para Homero y Dante, teniendo su correspondencia francesa en la secta desgajada del taller de David llamada de los «Primitifs» o «Barbus», capitaneados por Maurice Quaï ${ }^{1}$. Éstos acentúan dichas inclinaciones a la abstracción buscando un retorno hacia lo griego, tan radical que sólo encontraban modelos satisfactorios en la linealidad y abstracción de las pinturas de los vasos griegos, teniendo entre sus libros canónicos a los de Homero. Esta tendencia hacia la abstracción anticlásica y lineal

* Este artículo es fruto del Proyecto de Investigación BHA2000-1476 de la Dirección General de Investigación del Ministerio de Ciencia y Tecnología. Los autores desean agradecer a la Dr. ${ }^{a}$ D. ${ }^{a}$ Elvira Gangutia, Profesora de Investigación del Instituto de Filología del CSIC, y a D. ${ }^{a}$ Mercedes González-Amezúa, Conservadora del Museo de la Academia de San Fernando, la ayuda prestada para la realización de este trabajo.

1 Friedlaender, W.: De David a Delacroix, Madrid, 1989, pp. 53 a 56. 
influiría en el joven Ingres por la doble vía de la secta de los «Barbus» y Flaxman ${ }^{2}$. Producto de estos influjos son sus inmediatas y tempranas obras de Aquiles recibe a los embajadores de Agamenón (École de Beaux-Arts, Paris), elogiado por el propio Flaxman que estuvo en París en $1802^{3}$, y Venus herida por Diomedes (Kunstmuseum, Basilea), pintado aproximadamente entre 1805 y 1806, con claras influencias de Flaxman ${ }^{4}$.

Hecho este preámbulo, digamos que los asuntos homéricos en la pintura decimonónica española, tienen aquí su arranque, pues la llegada de José de Madrazo y Agudo (Santander, 1781-Madrid, 1859) a París en 1801 coincide con la efervescencia por lo griego, con el afán de buscar las auténticas fuentes de la Antigüedad clásica en Grecia, tanto por parte de su maestro David, como más radicalmente por la secta de los «Primitifs» y por su amigo y condiscípulo Ingres, coincidiendo también la llegada de Flaxman a París con su estancia en dicha ciudad.

Pues bien, en medio de este ambiente, nada de extraño tiene que, estando en el taller de David, eligiera como asunto para un premio de composición (que por cierto ganó) el de Aquiles rodeado de sus esclavas en el momento en que le anunciaron la muerte de su amigo Patroclo, dibujo cuya temática estaba sacada de los comienzos del canto XVIII de la Ilíada ${ }^{5}$, cuando Antíloco llega a la tienda de Aquiles, en el campamento griego, a anunciarle la muerte de su amigo Patroclo a manos de Héctor y la subsiguiente lucha que se desarrollaba entre aqueos y troyanos por el cadáver del mismo, texto que reproduciremos más adelante al tratar un cuadro de Tejeo de igual asunto, para evitar repeticiones. En este dibujo, vemos a Madrazo por primera vez buscar el mundo griego como auténtica fuente de la Antigüedad clásica, pero también ocuparse en un asunto de la Ilíada, lo que no deja de ser altamente significativo. Realizado a finales de 1801 o principios de 1802, bien pudo ser creado bajo la sugerencia arcaizante del arte practicado por su amigo Ingres en esos momentos, quien, en 1801, había ganado el Grand Prix de Roma con su cuadro antes mencionado de Aquiles recibe a los embajadores de Agamenón que debió de conocer, sin duda, Madrazo.

Una vez en Roma, volvería Madrazo al tema griego, y de nuevo con un asunto de la Ilíada de Homero; pero ahora con una obra de mayor empeño, el gran lienzo, de 2,736 × 7,26 metros, pintado al temple sobre lienzo, que realizó en 1812 para el Palacio pontificio de Monte Cavallo, del Quirinal, con el asunto de La disputa de griegos y troyanos por el cadáver de Patroclo. Este lienzo se le encargó a Madrazo con motivo de la visita de Napoleón a Roma, concretamente para decorar el segundo salón de representación de la emperatriz de la galería de Alejandro VII de dicho palacio, el cual debía de servir de residencia imperial. La estancia fue decorada con cuadros de Madrazo, Agricola, Conca e Ingres, siendonos conocido hoy sólo el de este último, que representa a Rómulo vencedor de Acrón (École de Beaux-Arts, París), que nos recuerda todavía esa tendencia a la abstracción lineal, ese ideal arcaizante, que caracterizó a sus cuadros realizados en París antes vistos. El contrato de Madrazo fue de los mejores, junto con el de Ingres, cobrando por el encargo la suma de tres mil francos ${ }^{6}$.

Como decimos, desconocemos hoy el cuadro de Madrazo, pues se ignora su paradero o suerte, pero, en compensación, sí nos es conocido el dibujo preparatorio del mismo (Fig. 1), gracias a Jordán de Urríes, quien deshizo el equívoco tradicional que venía atribuyendo como preparatorio del cuadro un dibujo del pintor italiano Antonio Raffaele Calliano (1785-1824)

\footnotetext{
${ }^{2}$ Ibidem, pp. 53 y 56.

${ }^{3}$ Ibidem, p. 73.

4 Ibidem

5 Jordán de Urríes, J.: «José de Madrazo en Italia (1803-1819)», Archivo Español de Arte, t. LXV, núms. 259-260, Madrid, 1992, p. 355. (Los versos que inspirarían esta composición se desarrollan entre el 1 y el 34 de dicho Canto XVIII).

6 Jordán de Urríes, J.: «José de Madrazo en Italia (1803-1819)», Archivo Español de Arte, t. LXVII, núm. 266, Madrid, 1994, p. 133.
}

AEA, LXXV, 2002, 299, pp. 237 a 253 


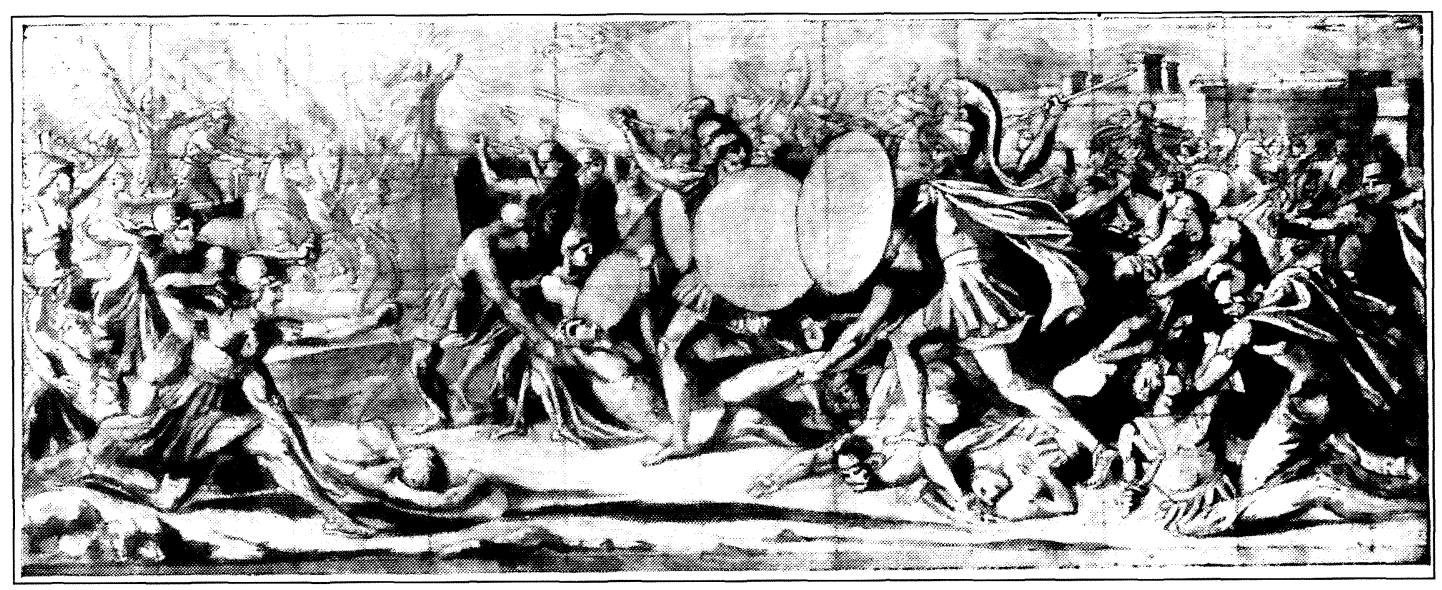

Fig. 1. José de Madrazo: La disputa de griegos y troyanos por el cadáver de Patroclo. Dibujo preparatorio. Antigua colección Ricardo de Madrazo.

sobre el mismo asunto que se conserva en el Museo del Prado; falsa atribución que arranca, a su juicio, de Bernardino de Pantorba, pasando así de autor en autor hasta que descubrió que el verdadero dibujo preparatorio había sido expuesto en la Exposición de Pinturas Españolas de la primera mitad del siglo XIX, organizada por la Sociedad Española de Amigos del Arte en 1913, en cuyo catálogo no se da ningún título de los dibujos de José de Madrazo allí exhibidos, propiedad de Ricardo de Madrazo, pero que Elías Tormo sí menciona en la crítica que de ella hizo: «De Madrazo se exponían (...), otro dibujo (de 1812) para el gran cuadro de Roma, en el Quirinal (griegos y troyanos disputándose el cuerpo de Patroclo)», como también lo hicieron Vegue y Goldoni y Sánchez Cantón, mientras que dicho dibujo se reproducía en un artículo de Garnelo y Alda sobre la citada exposición con el erróneo título de «El rapto de las Sabinas, dibujo de don José Madrazo» ${ }^{7}$. Que no aparezca ningún título de los dibujos de Madrazo expuestos en el catálogo de la exposición y que la reproducción del dibujo aparezca en ese artículo con el título cambiado, son los dos elementos fundamentales, junto con la falsa atribución de Bernardino de Pantorba, que han contribuido al tradicional error. Conocido así el auténtico dibujo preparatorio, presumiblemente, según Jordán de Urríes, éste no se diferenciaría demasiado de la pintura a juzgar por la cuadrícula que conserva ${ }^{8}$.

El tema de la obra está sacado del canto XVIII de la Ilíada, cuando Aquiles, tras conocer por medio de Antíloco la muerte de Patroclo a manos de Héctor y recibir el consejo de su madre Tetis de no salir al campo de batalla hasta que ella le llevase las nuevas armas que iba a encargar a Hefesto, recibe la recomendación de Hera, a través de la mensajera Iris, de salir al combate para recuperar el cuerpo de Patroclo que se estaban disputando griegos y troyanos; ante la negativa de Aquiles de armarse, Iris le sugiere que fuese hasta el foso del campamento griego y se mostrase a los troyanos con la intención de que atemorizados huyeran. Una vez que se marchó Iris: «Por su parte, Aquiles, caro a Zeus, se levantó. Atenea / le echó sobre sus valientes hombros la floqueada égida, / la diosa de la casta de Zeus coronó su cabeza de un nimbo / áureo e hizo brotar de su cuerpo una inflamada llama ardiente. / (...); / así el fulgor de la cabeza de Aquiles llegaba hasta el cielo. / Fue al borde del foso y se paró lejos del muro, mas a los aqueos / no se unió por deferencia hacia el sagaz encargo de su madre. / Allí se detuvo y dio un grito, que Palas Atenea a gran distancia / llevó, y causó un indecible tumulto

\footnotetext{
7 Todos los datos que anteceden están sacados de: Ibidem, pp. 133 y 134.

${ }^{8}$ Ibidem.(el dibujo está reproducido en la p. 135).
} 
entre los troyanos. / Como conspicuo es el son de la trompeta al sonar en presencia / de los enemigos, arrasadores de ánimos, que merodean la ciudad, / así de conspicua sonó entonces la voz del Eácida. / Nada más oír la broncínea voz del Eácida, / se conmovió el ánimo de todos: los caballos, de bellas crines, / giraban atrás los carros, presintiendo dolores en el ánimo; / y los aurigas quedaron atónitos al ver el infatigable fuego / que ardía sobre la cabeza del magnánimo Pelida / de modo terrible y que Atenea, la ojizarca diosa, inflamaba. / El divino Aquiles profirió tres enormes alaridos sobre la fosa, / y las tres veces troyanos e ínclitos aliados quedaron turbados. / Allí también perecieron entonces doce de los mejores mortales / al lado de sus carros y de sus picas; entre tanto los aqueos / sacaron jubilosos el cuerpo de Patroclo del alcance de los dardos / (...)» ${ }^{9}$. Aunque Jordán de Urí́es indica que el asunto del cuadro está tomado del Canto XVIII de la Ilíada y hace un breve resumen del hecho ${ }^{10}$, pero sin citar los versos de donde fue extraído, nosotros hemos preferido, de acuerdo con lo representado en el lienzo, buscar las estrofas del episodio en las que se inspiró Madrazo, para ver hasta que punto se ajustó en su composición a los versos que forman la escena que dio inspiración a su obra. Así, comparando el dibujo con las estrofas antes reproducidas, el resultado es que Madrazo hizo una ajustada interpretación de las mismas, pudiéndose ver a los aqueos en la parte izquierda y a los troyanos en la derecha, estando el cuerpo de Patroclo en la parte baja central de la composición agarrado de pies y manos por unos y otros contendientes; al fondo del espacio que se abre entre éstos, se puede ver la figura de Aquiles gritando, protegido por Atenea e irradiando llamas, en lo alto del muro del foso del campamento aqueo; en el fondo derecha, tras los combatientes de primer término, se ve girar en tumulto a los carros troyanos, asustados caballos y aurigas por la visión ígnea y sus terribles gritos, teniendo como telón la ciudad de Troya. Como podemos comprobar de la comparación, Madrazo realizó una fiel transcripción al lenguaje pictórico de la escena descrita en el texto literario.

Iconográficamente, al igual que en el caso de su celebérrimo cuadro de La muerte de Viriato, la parte central de la composición de este dibujo también tiene débitos de Flaxman, concretamente de ilustraciones de éste para la Iliada y las Tragedias de Esquilo, como apunta Jordán de Urríes ${ }^{11}$. Este autor y Díez nos aportan el juicio de Carderera sobre el cuadro, que quizá pudo ver en Roma: «Esta composición rica de figuras algo mayores que el natural, y el estilo y carácter heroico con que están dibujadas, revelan los grandes estudios que por el antiguo haría su autor» ${ }^{12}$. Sin embargo, a pesar de esta opinión de Carderera, el cuadro fue objeto de críticas adversas, sobre todo en lo referente a la dureza del color, aunque se reconocía su mérito en la composición y el dibujo ${ }^{13}$. Basándose en estos dos elementos, que son los que pueden analizarse a través del dibujo, Díez apunta que llega a recordar al Rapto de las Sabinas de David ${ }^{14}$.

De los otros pintores neoclásicos, discípulos de David en París al igual que Madrazo, del único que tenemos noticia de haber tratado un tema homérico es de José Aparicio Inglada (Alicante, 1770- Madrid, 1838), del que Ossorio y Bernard cita, entre sus principales obras, un cuadro con el asunto de La muerte de Patroclo ${ }^{15}$, tema tópico de la Ilíada, pero nada podemos argumentar sobre esta obra, ya que lo único de que disponemos al respecto es la escueta cita

\footnotetext{
${ }^{9}$ Homero: Ilíada, (traducción, prólogo y notas de Emilio Crespo Güemes), Ed. Gredos, Madrid, 1991, pp. 472 y 473, versos 203 a 232

${ }^{10}$ Jordán de Urríes, J.: Op. cit., nota 6, p. 134.

"Ibidem, pág. 134, nota 21.

12 Ibidem, p. 134; Díez, J. L. (dirección científica): José de Madrazo (1781-1859), Ayuntamiento de Madrid-Fundación Marcelino Botín, Santander, 1998, p. 92.

13 Jordán de Urríes, J.: Op. cit. nota 6, pp. 134 y 136; Díez, J. L.: Op. cit. nota 12, p. 93.

${ }^{14}$ Díez, J. L.: Op. cit. nota 12, p. 93.

${ }^{15}$ Ossorio y Bernard, M.: Galería biográfica de artistas españoles del siglo xIx, Madrid, 1883-1884, p. 42.

AEA, LXXV, 2002, 299, pp. 237 a 253
} 


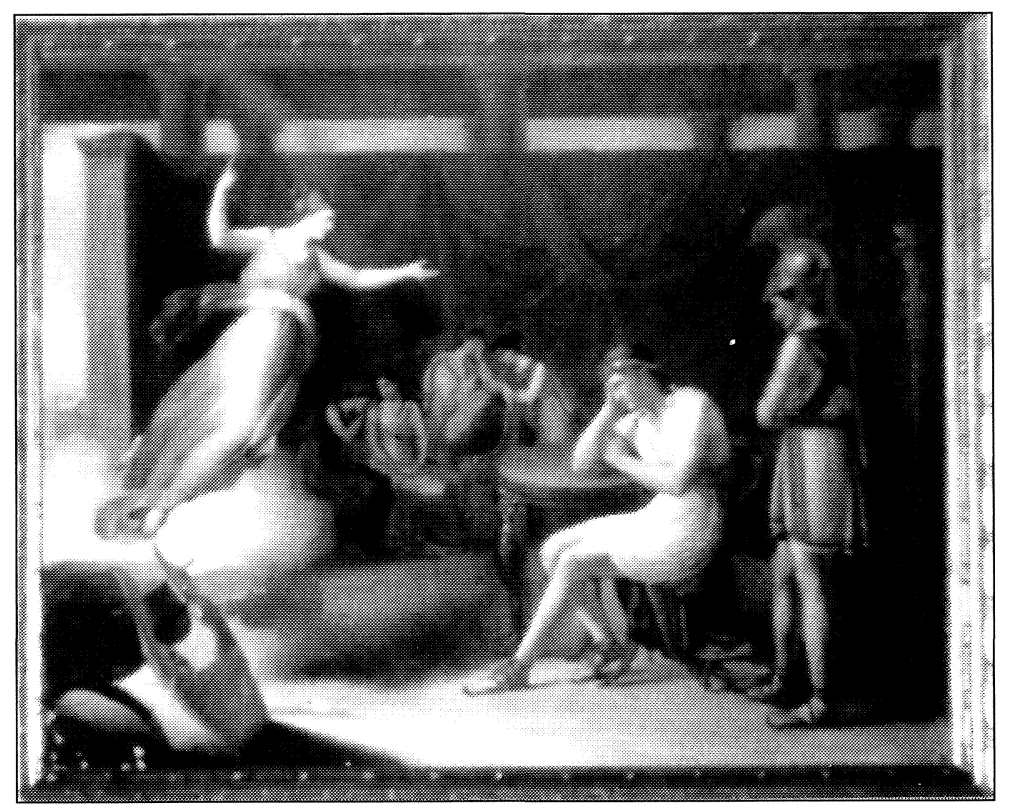

Fig. 2. Federico de Madrazo: Aquiles en su tienda en el momento en que Iris le manifiesta que acuda a libertar el cuerpo de Patroclo. Paradero desconocido.

que de su título hace Ossorio y Bernard. Sin embargo, lo específico de dicho título nos permite fácilmente especular sobre el momento del episodio representado en el lienzo. El Canto XVI de la Ilíada, narra la muerte de Patroclo entre los versos 783 y 863, abarcando la secuencia completa del episodio; o sea, desde que el amigo de Aquiles se lanza por última vez, en cuatro arremetidas sucesivas, contra los troyanos en el combate entablado con estos, hasta que Héctor arranca la lanza del cuerpo muerto de Patroclo ${ }^{16}$. En medio de estas dos escenas discurre la secuencia que nos narra como, tras las tres primeras arremetidas exitosas, en la cuarta el dios Febo Apolo, oculto en una tupida bruma, se acerca a Patroclo y golpeándole en la espalda le desprende del yelmo y de la armadura, quedando indefenso ante el lanzazo que le propina en la espalda el dárdano Euforbo Pantoida quien, a pesar de ello, rehuye el enfrentamiento con el guerrero griego, que retrocediendo busca la protección de las filas de los aqueos, pero «Héctor, nada más ver al magnánimo Patroclo / retrocediendo, herido por el agudo bronce, / llegó cerca de él entre las filas, le hirió con la lanza / en lo más bajo del ijar y le hundió el bronce de parte a parte. / Retumbó al caer y causó gran pesar a la tropa de los aqueos» ${ }^{17}$. Estos versos son los que pudieron servir de inspiración a Aparicio para componer el lienzo, quizá con algún aditamento secundario referente a la secuencia en que se inscribe la muerte de Patroclo; pero también le pudieron servir los que conforman la escena final de la secuencia, y con los que termina prácticamente el Canto XVI, en que, una vez muerto Patroclo y decir sus correspondientes palabras Héctor, se concluye: «Tras hablar así, arrancó [Héctor] la broncínea pica de la herida, / apoyando encima el pie, y lo apartó boca arriba de la lanza» ${ }^{18}$, posiblemente también con los mismos aditamentos secundarios a que nos referimos antes.

Próximo a estos neoclásicos davidianos, y especialmente a José de Madrazo, su padre, tenemos el cuadro juvenil de Federico de Madrazo (Roma, 1815-Madrid, 1894) Aquiles en su tienda en el momento en que Iris le manifiesta que acuda a libertar el cuerpo de Patroclo (Fig. 2).

\footnotetext{
${ }^{16}$ Homero: Op. cit. nota 9, pp. 439 a 441 .

17 Ibidem, p. 440 (versos del 818 al 822).

18 Ibidem, p. 441 (versos 862 y 863 ).
} 
Según la relación que de sus obras hace Ossorio y Bernard, se trata de su segundo cuadro de composición, situándolo entre La Resurrección del Señor, terminado por el pintor a sus catorce años de edad, en 1829, y La continencia de Escipión, realizado a los dieciséis, en 1831, por el que fue nombrado académico de mérito de la Real Academia de Bellas Artes de San Fernando a tan temprana edad ${ }^{19}$. Díez, por tanto, lo fecha entre 1829 y 1830 , siendo ejecutado por Madrazo a los quince años de edad ${ }^{20}$. Es claro que, en estos primeros años, antes de su formación romántica en París y Roma, Federico de Madrazo aborda temas caros al neoclasicismo, sin duda por influencia de su padre que tan importante papel jugó en su instrucción. No creemos que sea casual el hecho de que el asunto de esta obra esté extraído de la Ilíada, y menos cuando el pasaje aquí representado es inmediatamente posterior al del dibujo que su padre realizó en el taller de David en París, por el que ganó un premio de composición, figurando a Aquiles rodeado de sus esclavas en el momento en que le anunciaron la muerte de su amigo Patroclo, e inmediatamente anterior al tema del cuadro que el mismo José de Madrazo realizó para el palacio del Quirinal de Roma de La disputa de griegos y troyanos por el cadáver de Patroclo, como antes vimos. De hecho, los tres pasajes son cronológicamente consecutivos al comienzo del Canto XVIII de la Ilíada ${ }^{21}$. Por ello creemos que José de Madrazo tuvo bastante que ver tanto en la elección del asunto de este cuadro por parte de su hijo, como en la misma técnica, profundamente neoclásica, según veremos, con que lo realizó.

Este cuadro juvenil de Federico de Madrazo, que tiene el interés de ser de las pocas obras de composición que, lamentablemente, realizó en su vida, lo guardó consigo el artista hasta su muerte, y aunque se halla hoy en paradero desconocido, sin embargo podemos saber como era gracias a una fotografía recientemente aparecida que publicó Díez ${ }^{22}$, quien nos dice que la escena que ilustra es descrita por Ochoa, el cuñado de Federico, en los siguientes términos: «Este cuadro representa á Aquiles en su tienda, sumerjido en la aflicción y rodeado de sus esclavas, en el momento en que la mensagera Iris le dice que vaya á libertar el cuerpo de Patroclo, que sin su ausilio quedaría presa de los troyanos» ${ }^{23}$. La descripción de Ochoa no viene a ser más explícita que el título del cuadro, añadiendo simplemente alguna escueta precisión acompañada de algún epíteto, acordándose perfectamente ambos, junto con el mismo lienzo, al que conocemos por la fotografía antes citada, con el texto de la Ilíada de donde fue extraído, correspondiente al Canto XVIII, como decimos, en que ante el acoso cada vez más acuciante de Héctor y los troyanos al cadáver de Patroclo, defendido difícilmente por los dos Ayantes y los aqueos, acude Iris a instar a Aquiles: «Y lo habría sacado [Héctor] y se habría alzado con indecible gloria, / de no ser porque la rápida Iris, de pies como el viento, / llegó corriendo del Olimpo a anunciar a Aquiles que se armara / a ocultas de Zeus y de los demás dioses, según encargo de Hera. / Y deteniéndose cerca, le dijo estas aladas palabras: / $<_{i}$ Muévete, Pelida, el más terrorífico de todos los hombres! / Defiende el cuerpo de Patroclo, por el que una atroz contienda / se libra delante de las naves. Mortandad mutua se causan, / éstos por defender el cuerpo del guerrero muerto, / mientras los troyanos para arrastrarlo a la ventosa Ilio / cargan derechos. El esclarecido Héctor es el que más / ansía tirar de él; y su ánimo le impele a clavarle la cabeza / en lo alto de la empalizada, tras cortar su delicado cuello. / ¡Ea, arriba! ¡No sigas tendido! Sienta tu ánimo escrúpulos / de que Patroclo se convierta en juguete de las perras troyanas. / Para ti sería una afrenta si va mutilado a unirse con los muertos. $>{ }^{24}$. Aunque después continúa la

\footnotetext{
19 Ossorio y Bernard, M.: Op. cit. nota 15, p. 402.

${ }^{20}$ Díez, J. L. (dirección científica): Federico de Madrazo y Kuntz (1815-1894), Museo del Prado, Madrid, 1994, pp. 49-50.

${ }^{21}$ Homero: Op. cit. nota 9, pp. 466 a 473 (versos 5 a 233 ).

22 Díez, J. L.: Op. cit. nota 20, p. 49.

${ }^{23}$ Ibidem, pp. 49-50.

${ }^{24}$ Homero: Op. cit. nota 9, pp. 471 y 472
}

AEA, LXXV, 200̀2, 299, pp. 237 a 253 
conversación mantenida entre Iris y Aquiles al respecto, éste es el momento exacto del pasaje que representa el cuadro de Madrazo, según la fotografía que conocemos, permitiéndose, sin embargo, el pintor la licencia de representar sentado al héroe, muy pulcro y acicalado, no respondiendo a la realidad del pasaje literario, ya que Aquiles, al enterarse por Antíloco de la muerte de Patroclo, se cubrió de negro hollín la cabeza y la túnica, revolcándose además, extendido, sobre el polvo, estado y postura deplorables en que lo encuentra la diosa Iris, según vemos en el texto. Aparte esta licencia de puro neoclasicismo pictórico, el resto de la composición concuerda perfectamente con el pasaje literario: la diosa Iris sobre una nube en calidad de mensajera de los dioses, las mujeres que se ven al fondo son las esclavas afligidas de Aquiles y Patroclo, las cuales se encontraban presentes en el momento en que le comunica la muerte de Patroclo el mensajero Antíloco, quien sin duda está también representado en el guerrero armado que, detrás de Aquiles, ocupa todo el lateral derecho del lienzo, ya que Antíloco venía directamente del combate y estuvo presente durante los momentos de desesperación del héroe, por lo que no creemos que se trate de uno de sus oficiales según opinión de Díez ${ }^{25}$. La lira, apoyada en un taburete en el ángulo inferior izquierdo del lienzo, es, como dice Díez, el instrumento predilecto del héroe griego ${ }^{26}$, o sea, el atributo que lo personifica en el relato pictórico. En el análisis estilístico que este autor nos hace del cuadro, nos indica acertadamente que fue ejecutado por el joven Federico siguiendo literalmente el lenguaje neoclásico de las obras de su padre, pero con un mayor refinamiento en el modelado de los ropajes y en el claroscuro, añadiéndonos que «La distribución de las figuras en el espacio, la estructura clara y ordenada de la composición y el cuidado diseño de las figuras, tanto en el tratamiento de las anatomías como en la contención solemne de la expresión de los afectos, hacen indiscutiblemente de esta pintura una pieza de indudable significación en el modesto panorama de la pintura neoclásica española» ${ }^{27}$, con lo que estamos plenamente de acuerdo.

El mundo de la Ilíada tuvo también sus representaciones pictóricas en lo que denominaríamos como la estela del neoclasicismo, o sea, en ese clasicismo que sobrevive en el romanticismo interrelacionándose con él. Este es el caso de Rafael Tejeo (Caravaca, Murcia, 1798-Madrid, 1856), discípulo de José Aparicio en Madrid, de quien conocemos al menos dos obras de temática de la Ilíada, una representando a Antíloco llevando a Aquiles la noticia del combate trabado por los griegos contra los troyanos para obtener el cuerpo de Patroclo, y la otra con el asunto de Diomedes conducido por Minerva hiere a Marte, que son citadas por Ossorio y Bernard entre las principales obras del pintor, precisándonos, además, dicho autor que fueron pintadas por encargo del infante D. Sebastián Gabriel de Borbón y que figuraron en la Exposición del Liceo Artístico y Literario Español de Madrid de $1846^{28}$.

Pues bien, de estas dos obras tenemos la suerte de conocer al menos una, nos referimos a la titulada Antíloco llevando a Aquiles la noticia del combate trabado por los griegos contra los troyanos para obtener el cuerpo de Patroclo (Fig. 3) $(1,81 \times 2,53$ m., colección particular, Madrid), que ha sido publicada por Díez con el título de Aquiles recibiendo la noticia de la muerte de Patroclo, pero sin dar sus dimensiones ${ }^{29}$, aclarándonos en nota que estuvo inventariado en el Museo de la Trinidad («T. 322») ${ }^{30}$. El mencionado autor nos dice, respecto a la técnica y composición de la obra, que en ella perviven inmutables las fórmulas académicas de

\footnotetext{
${ }^{25}$ Díez, J. L.: Op. cit. nota 20, p. 50.

26 Ibidem.

27 Ibidem.

${ }^{28}$ Ossorio y Bernard, M.: Op. cit. nota 15, p. 659.

29 Díez, J. L. (dirección científica): La pintura de historia del siglo XIX en España, Museo del Prado, Madrid, 1992, pp. 74 y 75 (reproducido). Posteriormente lo publicó también, con el título de Aquiles jura vengar la muerte de Patroclo, Arias Anglés, E. «Rafael Tejeo Díaz», en VV.AA. De la Edad Media al Romanticismo, Caylus, Madrid, 1993, p. 208 , fig. 2

${ }^{30}$ Díez, J. L.: Op. Cit. nota 29, p. 100, nota 17.
}

AEA, LXXV, 2002, 299, pp. 237 a 253 


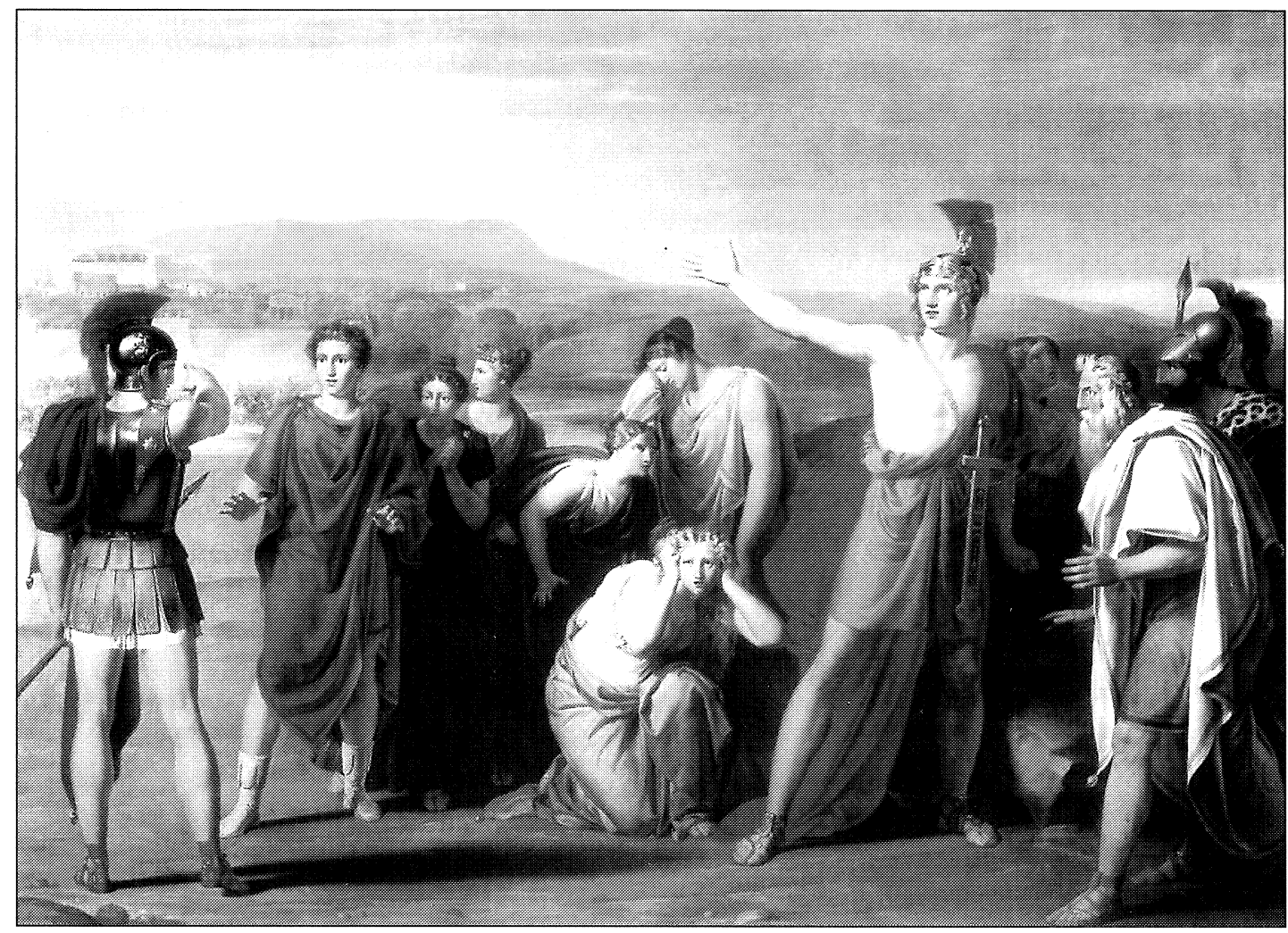

Fig. 3. Rafael Tejeo: Antíloco llevando a Aquiles la noticia del combate trabado por los griegos contra los troyanos para obtener el cuerpo de Patroclo. Colección particular. Madrid.

principios de siglo, pero «interpretadas por este artista con la cuidada factura y el modelado monumental y grandioso de las figuras característicos de su estilo» ${ }^{31}$. En efecto, el cuadro es de un neoclasicismo acendrado, tanto en el valor concedido al dibujo como en el frío colorido que resalta unos volúmenes casi estatuarios; igualmente en el tono declamatorio de la composición, en cuyo friso apretado de figuras, la única tensión estriba prácticamente en la contraposición de las dos figuras protagonistas de la escena, Antíloco de espaldas al espectador y Aquiles de frente. El ámbito se tiñe con un ligero matiz romántico por medio de las luces crepusculares que bañan la escena y, sobre todo, a ese hermoso paisaje, tan neoclásico también, con la ciudad de troya y su campiña de fondo. El deseo de reconstrucción arqueológica está patente en todos los elementos del cuadro. El sentido homérico pretendido se encuentra plenamente logrado y la valoración de lo griego como auténtica fuente de la Antigüedad está plenamente presente en esta preciosa obra que, desde luego, es pieza también de indudable significación en el modesto panorama del neoclasicismo español, aunque sea, en este caso, algo tardío.

En cuanto al asunto representado, se refiere a la escena que se desarrolla al comienzo del canto XVIII de la Ilíada, cuando Antíloco llega junto a Aquiles a comunicarle la muerte de Patroclo y la lucha que desarrollaban griegos y troyanos por su cadáver: «Mientras resolvía estas dudas en la mente y en el ánimo, / llegó cerca de él [Aquiles] el hijo del admirable Nestor / derramando cálidas lágrimas y le comunicó la dolorosa noticia: / < iAy de mi, hijo del belicoso Peleo! Muy luctuosa es / la nueva que ahora vas a saber y que ojalá no hubiera suce-

${ }^{31}$ Ibidem, p. 74.

$A E A, \mathrm{LXXV}, 2002,299$, pp. 237 a 253 
dido. / Patroclo yace muerto y ya se lucha alrededor de su cadáver / desnudo, que las armas las tiene Héctor, de tremolante penacho.> / Así habló, y a él una negra nube de aflicción lo envolvió» ${ }^{32}$. Estos versos están perfectamente recogidos en el cuadro en las figuras y actitudes de los dos protagonistas de la escena, Antíloco y Aquiles; el resto de la composición, que está formada fundamentalmente por los personajes que corifican dicha escena, y que representan la compañía en que se encontraba Aquiles cuando Antíloco le comunica la funesta noticia, se halla también expresada en ese Canto XVIII unos versos más adelante de los anteriormente citados: «Las siervas que Aquiles y Patroclo se habían adjudicado en prenda / proferían grandes alaridos afligidas en su corazón, y a la puerta / corrieron en torno del belicoso Aquiles y todas, con las manos / mientras se golpeaban el pecho, cayeron postradas de hinojos.» ${ }^{33}$. A ello añade el pintor un paisaje crepuscular, de acuerdo con el momento del día en que transcurre el pasaje literario, en el que se ve al fondo izquierda la ciudad de Troya y, a medio camino entre los muros de ésta y el del campamento aqueo, el desarrollo del combate de unos y otros por el cuerpo de Patroclo. Vemos, pues, que, en general, el pintor siguió bastante fielmente el texto de Homero correspondiente a este episodio, si bien añadiendo de su propia cosecha, un anciano y un guerrero en el lateral derecho del cuadro, para expresar, de alguna manera, que el lugar en que se desarrolla la escena es el campamento griego frente a los muros de Ilion.

Este episodio de la Ilíada pintado por Tejeo, es el mismo que tomó José de Madrazo para representar en el dibujo con el que ganó el premio de composición en el taller de David, que antes vimos, y que tituló Aquiles rodeado de sus esclavas en el momento en que le anunciaron la muerte de su amigo Patroclo; lo que no quiere decir que la composición de dicho dibujo de Madrazo y la del cuadro de Tejeo fuesen iguales, por supuesto, pero sí que, al narrar el mismo episodio, que es un momento muy determinado y corto al comienzo del referido Canto XVIII, tuviesen forzosamente la similitud que proporciona el utilizar el mismo texto de inspiración, que tiene, por lo dicho, unos elementos muy concretos que necesariamente habrían de ser tomados por cualquier pintor que abordase la representación de los hechos narrados en esos versos. Prueba de ello es que el título del dibujo de Madrazo podría aplicarse con facilidad al cuadro de Tejeo sin que discordase.

El otro cuadro de Tejeo que aborda un tema de la Ilíada lleva por título el de Diomedes conducido por Minerva hiere a Marte, como antes vimos, y que, como también dijimos, nos es hoy día desconocido. Sin embargo, pensamos que, al ser ambas obras pintadas por encargo del infante D. Sebastián Gabriel de Borbón y exhibidas las dos en la Exposición del Liceo Artístico y Literario Español de Madrid de 1846, fuesen muy probablemente pareja. No deja de llamar la atención el hecho de que el pintor utilice los nombres latinos de los dioses griegos, quizá porque la traducción de la Ilíada de que se sirvió utilizaba los nombres latinizados de las deidades, por ser éstos mas accesibles al público en general dado su mayor arraigo tradicional.

El cuadro, como decimos, está hoy día en paradero desconocido y, por tanto, no podemos saber cómo fuese. Pero tenemos la suerte de que su título sea lo suficientemente explícito como para poder aventurar el momento preciso que representaría la escena. En efecto, el Canto V de la Ilíada y el comienzo del VI relatan las hazañas de Diomedes, y concretamente en el Canto $\mathrm{V}$ se nos narran los dos combates en que el Tidida hiere, ayudado por Atenea, a dos dioses, Afrodita y Ares respectiva y sucesivamente.

Es este tema de Diomedes hiriendo a los dioses uno de los pasajes de la Ilíada preferidos por los pintores, junto con el de la muerte de Patroclo. Ya vimos anteriormente como el joven Ingres representó a Venus herida por Diomedes (Kunstmuseum, Basilea) sobre 1805-1806, asunto ex-

${ }^{32}$ Homero: Op. Cit. nota 9, pp. 466 y 467 (versos 15 a 22).

${ }^{33}$ Ibidem, p. 467 (versos 28 a 31 ).

$A E A, \mathrm{LXXV}, 2002,299$, pp. 237 a 253 
traído de ese Canto V de la Ilíada, cuando Afrodita herida por Diomedes se retira del combate ayudada por Iris y solicita a Ares que le preste sus caballos y carro para huir al Olimpo. El episodio concretamente representado por Ingres se desarrolla entre los versos 352 y $365^{34}$, de los que el momento exacto plasmado por el pintor es cuando Iris ayuda a Afrodita a montar en el carro de Ares, quien aparece junto a la cuadriga, o sea, los versos 363, 364 y 365 rigurosamente ${ }^{35}$.

Pues bien, el cuadro de Tejeo nos narra como Diomedes hirió a Ares, asunto que se desarrolla entre los versos 825 y 863 de ese Canto V. El episodio comienza cuando Atenea, decidida a apoyar a Diomedes contra Ares, echa de un manotazo del carro de aquel a Esténelo, el auriga del Tidida, y ocupa su lugar. Oculta por el yelmo de Hades dirige el carro contra Ares, que despojaba de sus armas al cadáver de Perifante, a quien había dado muerte en la batalla. El dios, viendose venir a Diomedes encima, marchó directamente contra él: «Cuando ya estaban cerca, avanzando el uno contra el otro, / Ares se aupó primero sobre el yugo y las riendas de los caballos / con la broncínea pica, ávido de quitarle el aliento vital. / Atenea, la ojizarca diosa, la agarró con la mano / y la empujó bajo la caja del carro, haciendo su impulso baldío. / El segundo se lanzó Diomedes, valeroso en el grito de guerra, / con la broncínea pica. Imprimióle ahínco Palas Atenea / hacia el extremo más bajo del ijar, donde se ceñía la ventrera, / y allí lo alcanzó e hirió. Desgarró su bella piel / y luego arrancó la lanza; y bramó el broncíneo Ares / con un alarido como el que profieren nueve mil o diez mil / hombres en el combate, cuando traban marcial disputa. / El temblor sobrecogió a aqueos y troyanos, presas de miedo: $/$ ¡ con tal potencia bramó Ares, insaciable de combate!» ${ }^{36}$. De estos versos citados saldría el momento exacto de la representación de Tejeo, muy probablemente el instante en que le clava la lanza Diomedes a Ares, llevando a Atenea de auriga con el yelmo de Hades calado.

Otros de los asuntos de la Ilíada que gozaron de representación pictórica, dado su carácter dramático y simpatía del héroe, son los referentes al líder troyano Héctor. No nos consta que fuese tema abordado por destacados pintores españoles decimonónicos, pero conocemos un par de cuadros sobre el asunto, realizados por dos artistas que, a pesar de que hoy nos sean poco conocidos, no dejan de tener interés e, incluso, cierta calidad uno de ellos.

El primero, en el desarrollo cronológico de los acontecimientos, es el que representa la Despedida de Héctor y Andrómaca (Fig. 4) (1,38 × 1,95 m., Academia de San Fernando, Madrid, n. ${ }^{\circ}$ inv. 282), publicado como anónimo por Pérez Sánchez ${ }^{37}$ e identificado como de Julián Verdú (Alcoy, Alicante, ?-Madrid, 1846) por Ciruelos Gonzalo y Durá Ojea, quien solicitó en 1825 el ser nombrado académico de mérito de dicha institución, eligiendo, entre los temas propuestos, el de Hector despidiéndose de Andrómaca para salir al campo contra los Acheos, no siendo nombrado académico hasta 1828 por haber sido sometido a depuración por motivos políticos, lo que demoró el proceso. Por ello, entre el ejercicio de prueba (o sea, el dibujo preparatorio), firmado y fechado en 1825 (Academia de San Fernando, Madrid, n. ${ }^{\circ}$ inv. 2258 / P), y el cuadro definitivo, entregado en 1828, existen notables diferencias introducidas, entretanto, por el pintor, como son el trasladar la escena desde un interior a un exterior, para acordarla con el texto de la Ilíada del que está sacado el asunto, el aumento de los personajes y el cambio de posturas de la mayoría de los mismos, aunque respetando bastante la composición inicial ${ }^{38}$.

\footnotetext{
34 Ibidem, pp.195 y 196.

35 Ibidem, p. 196.

36 Ibidem, pp. 210 y 211 ( versos 850 a 863 ).

${ }^{37}$ Pérez Sánchez, A. E.: «Real Academia de Bellas Artes de San Fernando. Inventario de las pinturas», Academia, núm. 18, Madrid, 1964, p. 32, núm. 282.

${ }^{38}$ Todas las noticias que anteceden sobre la problemática de este cuadro están sacadas de Ciruelos Gonzalo, A. y Durá Ojea, M. V.: «Nuevos datos sobre pinturas y dibujos de la Real Academia de Bellas Artes de San Fernando», Academia, núm. 79, Madrid, 1994, pp. 327 y 328.
}

$A E A, \mathrm{LXXV}, 2002,299$, pp. 237 a 253 


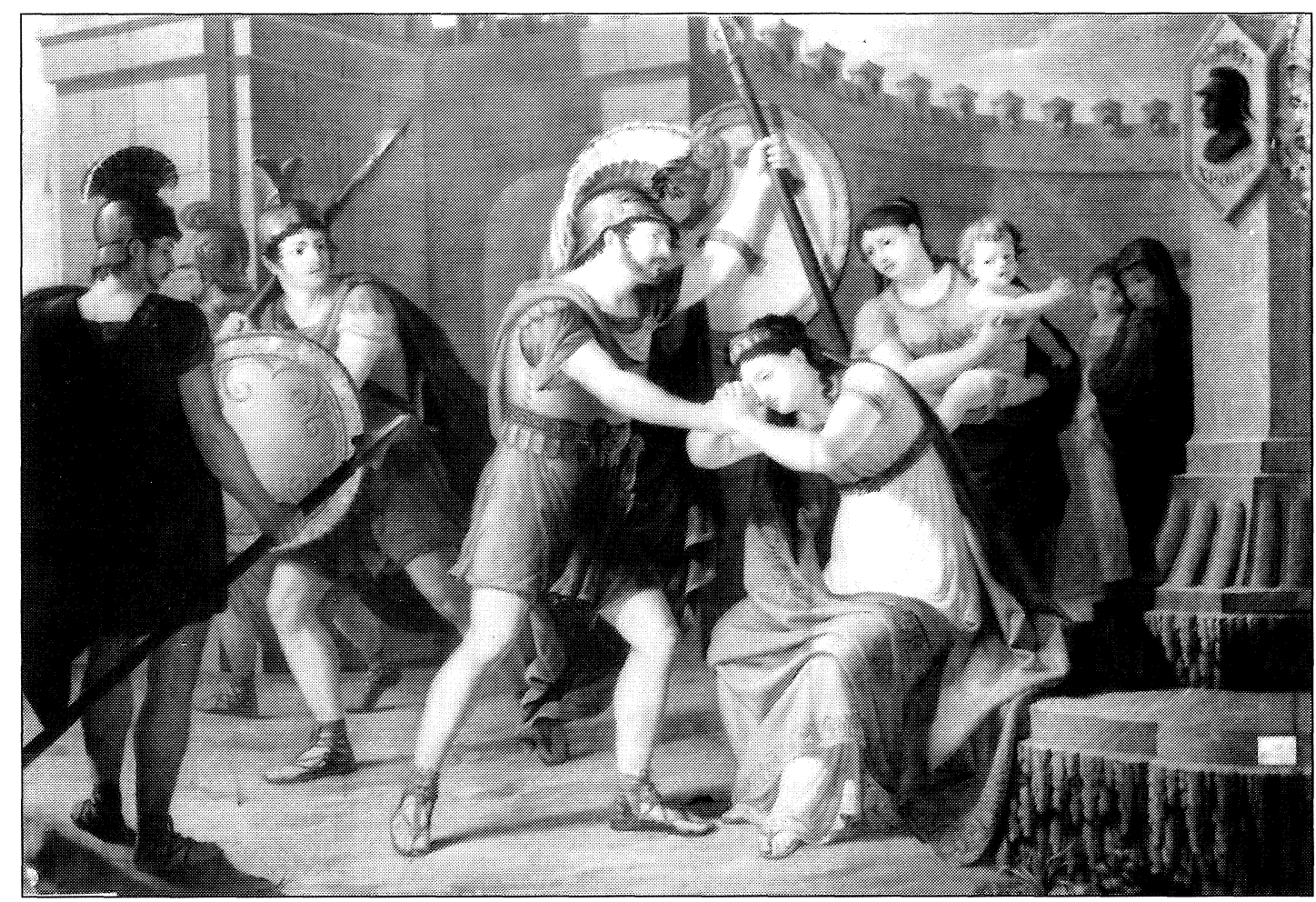

Fig. 4. Julián Verdú: Despedida de Héctor y Andrómaca. Museo de la Real Academia de Bellas Artes de San Fernando. Madrid.

Como pintura es obra de un neoclasicismo un tanto mediocre, pues, a pesar del intento de reconstrucción arqueológica en los atuendos de los personajes, no deja de tener aún un cierto aire dieciochesco, tanto en alguno de estos detalles como en la concepción de las figuras y en la composición, es decir, en la forma de narrar la escena en general. Este aire algo arcaizante se acentúa, sobre todo, en los yelmos, en las lanzas y en los rostros de los guerreros, e igualmente en las posturas de éstos, especialmente en la del que se halla de espaldas en el lateral izquierdo del cuadro, con los pies en compás, recordando actitudes que se remontan a ciertas de la pintura española del siglo xvir; también la muralla de la ciudad de Troya no corresponde con los conocimientos arqueológicos que al respecto se tenían ya en el siglo XIX. Y, aunque el dibujo, base de la composición, no deja de tener cierta calidad, no basta para sostener una obra en la que la concepción de las figuras y la narración compositiva resultan algo débiles.

Sin embargo, a pesar de la declamatoria falta de fuerza, el asunto sigue bastante fielmente el pasaje de la Ilíada de donde fue extraído, que corresponde al final del Canto VI. En efecto, ante el empuje de los aqueos y de Diomedes que, como antes vimos, llegó a herir a dos dioses partidarios de los troyanos en el Canto V, Héctor es enviado dentro de Troya con la misión de que emprendieran las damas troyanas rogativas desesperadas a la diosa Atenea, con el fin de que ésta detuviera el furioso ataque de sus protegidos los aqueos. Héctor tras visitar a su madre y a Helena y Paris, para recabar la ayuda de éste en el combate, marcha a su casa a visitar a Casandra su mujer y a su hijo Astianacte, a quienes no encuentra, pues han subido, junto con la nodriza del niño, a la torre más alta de la ciudad para contemplar la situación desesperada del feroz combate. Decide entonces salir de la ciudad y volver a la batalla con sus compañeros, pero «Cuando atravesó la gran ciudad y llegó a las puertas / Esceas, por donde se disponía salir a la llanura, / allí le salió al paso corriendo su esposa, rica en regalos, / Andrómaca, la 
hija del magnánimo Eetión, / (...). / Le salió entonces al paso, y con ella se acercó la sirvienta, / llevando en su regazo al delicado niño, todavía sin habla, / el preciado Hectórida, semejante a un bello astro. / (...). / Éste [Héctor] sonrió mirando al niño en silencio, / y Andrómaca se detuvo cerca, derramando lágrimas; / le asió la mano, lo llamó con todos sus nombres y le dijo: / <iDesdichado! Tu furia te perderá. Ni siquiera te apiadas / de tu tierno niño ni de mí, infortunada, que pronto viuda / de ti quedaré. Pues pronto te matarán los aqueos, / atacándote todos a la vez. Y para mí mejor sería, / si te pierdo, sumergirme bajo tierra. Pues ya no / habrá otro consuelo, cuando cumplas tu hado, / sino sólo sufrimientos. No tengo padre ni augusta madre: (...) [Pasa Andrómaca a continuación a narrar como Aquiles mató a su padre y hermanos y llevó prisionera a su madre que luego mató también Ártemis, y concluye] (...). ¡Oh Héctor! Tu eres para mí mi padre y mi augusta madre, / y también mi hermano, y tu eres mi lozano esposo. / Ea, compadécete ahora y quédate aquí, sobre la torre. / No dejes a tu niño huérfano, ni viuda a tu mujer. (...).» ${ }^{39}$.

Este es, sin duda, el momento clave representado en la composición pictórica, que intenta también incluir la hermosa respuesta que, a continuación, da Héctor a su esposa, ya que se nos representa al héroe troyano en actitud tan declamatoria y expresión del rostro tan dolida que parece estar dando sus razones a Andrómaca, razones en las que prima la valentía frente a la vergüenza de la cobardía y el amor a la gloria familiar y personal, añadiendole que si un día cayese Troya, no le importaría tanto el dolor de los troyanos «como el tuyo, cuando uno de los aqueos, de broncíneas túnicas, / te lleve envuelta en lágrimas y te prive del día de la libertad; / y quizá en Argos tejas la tela por encargo de una extraña / y quizá vayas por agua a la fuente Meseide o a la Hiperea / obligada a muchas penas, y puede que te acose feroz necesidad. / Y alguna vez quizá diga alguien al verte derramar lágrimas: / <Ésta es la mujer de Héctor, el que descollaba en la lucha sobre / los troyanos, domadores de caballos, cuando se batían por Ilio.> / Así dirá alguien alguna vez, y tu sentirás un renovado dolor / por la falta del marido que te proteja del día de la esclavitud. / Mas ojalá que un montón de tierra me oculte, ya muerto, / antes de oír tu grito y ver cómo te arrastran» ${ }^{40}$.

Tampoco se le pasa por alto al pintor el tierno detalle del niño asustado en brazos de la nodriza por el imponente aspecto de su padre armado que, a continuación de estas palabras que perfectamente puede estar declamando el personaje del cuadro- se desarrolla en el texto del pasaje homérico: «Tras hablar así, el preclaro Héctor se estiró hacia su hijo. / Y el niño hacia el regazo de la nodriza, de bello ceñidor, / retrocedió con un grito, asustado del aspecto de su padre. / Lo intimidaron el bronce y el penacho de crines de caballo, / al verlo oscilar temiblemente desde la cima del casco» ${ }^{41}$. Es claro en el cuadro que el pintor quiso introducir en la composición este detalle del texto literario, pues, en efecto, vemos al niño, asustado en brazos de su nodriza, intentando huir del aspecto que presenta su padre. Si bien, este es un instante posterior a la conversación mantenida por los cónyuges en el texto literario, pero que el pintor incluye en ese momento ante la limitación del lenguaje pictórico para expresar hechos sucesivos en una misma escena, pues el detalle del niño implica ya que Héctor deja de hablar con su mujer y tiende los brazos a su hijo que le rechaza asustado, lo que no podemos ver en el cuadro. Resumiendo, la escena pictórica intenta incluir la conversación mantenida por ambos cónyuges en su encuentro, tanto la alocución de Andrómaca como la respuesta de Héctor, incluyendo también el detalle del niño asustado, o sea, tres momentos consecutivos del texto unidos, por necesidad del lenguaje pictórico, en un mismo instante. Es este pasaje de la

\footnotetext{
39 Homero: Op. Cit. nota 9, pp. 225 y 226 (versos 392 a 432).

40 Ibidem, pp. 226 y 227 (versos 440 a 465 ).

${ }^{41}$ Ibidem, p. 227 (versos 466 a 470). 


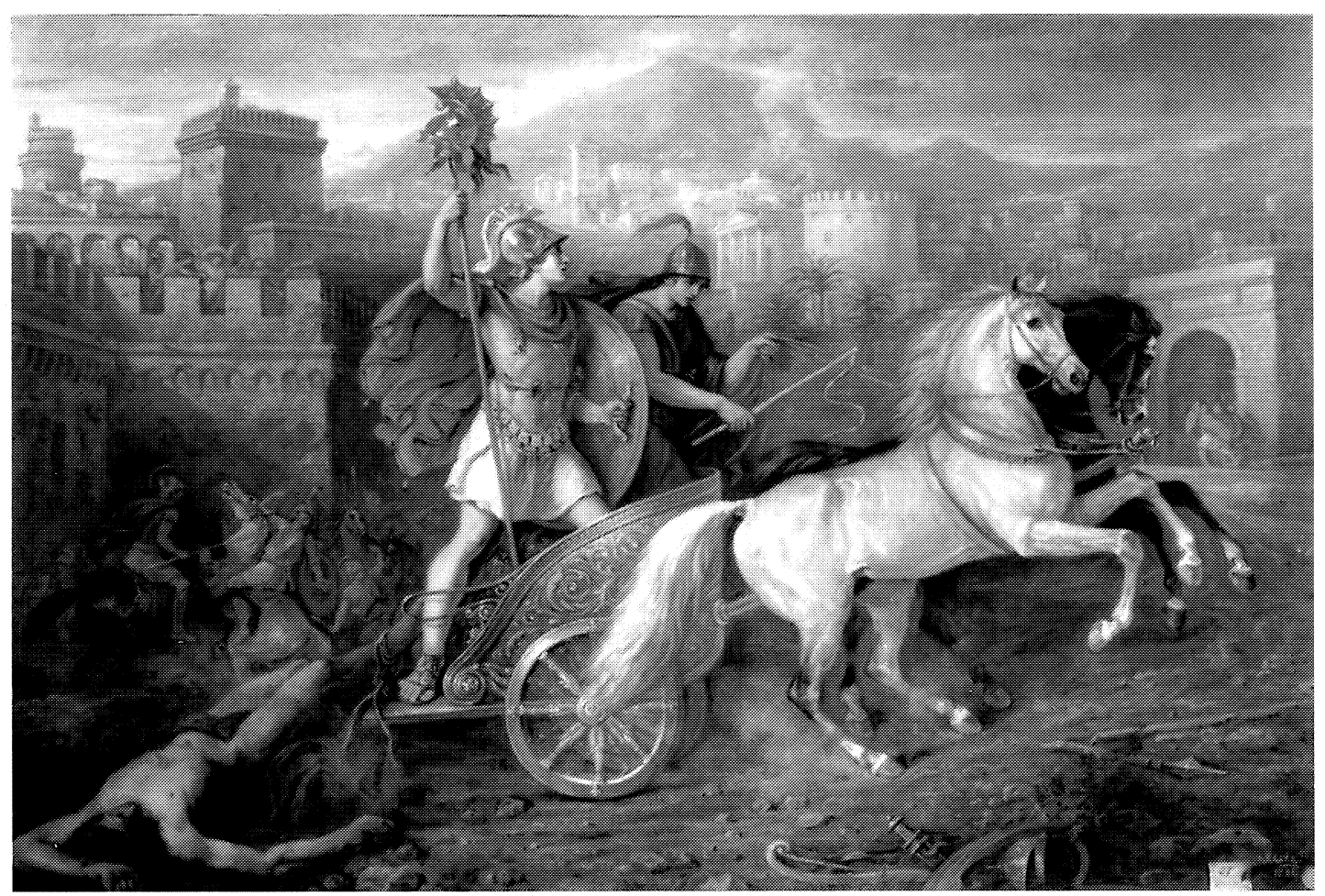

Fig. 5. José Schmitz Calvete: Aquiles arrastrando, atado a su carro, el cadáver de Héctor. Museo de la Real Academia de Bellas Artes de San Fernando. Madrid.

despedida de Héctor y Andrómaca uno de los más bellos de la Ilíada por su fuerza dramática, humanidad y ternura, lleno de simpatía hacia sus protagonistas. Hubiera merecido mejor pintor para representarlo, pero prueba, de todas formas, la superioridad de la palabra escrita para expresar y mover los sentimientos, así como para despertar imágenes en la mente del que recibe su mensaje.

El otro cuadro referente al héroe troyano Héctor, al que antes nos referimos, es del pintor José Schmitz Calvete, obra a la que hace referencia Ossorio y Bernard al ocuparse de la brevísima biografía que le dedica al artista y que se reduce prácticamente a los términos en que explica el porqué había llegado a su conocimiento, ya que en 1881 la Real Academia de San Fernando nombró a Schmitz por aclamaciớn su individuo honorario, pues, contando más de noventa años de edad, era el decano de los pintores españoles; en prueba de gratitud regaló a la corporación un cuadro representando a Aquiles arrastrando, atado a su carro, el cadáver de Héctor (Fig. 5), única obra de este artista de que tenía noticia ${ }^{42}$. Este cuadro fue publicado por Pérez Sánchez como de J. Schnitz ${ }^{43}$-porque así se lee en la firma que lleva el lienzo-, dándole el título de Aquiles con el cadáver de Héctor $(1,20 \times 1,78 \mathrm{~m}$., firmado y fechado, interpretando correctamente el nombre, «J. Schmitz 1881», Academia de San Fernando, Madrid, n. ${ }^{\circ}$ inv. 258). Ciruelos Gonzalo y Durá Ojea que fijan su identificación a través de Ossorio y Bernard y completan la ficha de la obra, nos dicen que el 14 de noviembre de 1881 el Director presentó en sesión ordinaria el cuadro de Schmitz Aquiles arrastrando a Héctor ante los muros de Troya que regalaba a la Academia por su nombramiento ${ }^{44}$.

42 Ossorio y Bernard, M.: Op. Cit. nota 15, p. 635.

${ }^{43}$ Pérez Sánchez, A. E.: Op. Cit. nota 37, p. 31, núm. 258.

${ }^{44}$ Ciruelos Gonzalo, A. y Durá Ojea, M. V.: Op. Cit. nota 38, pp. 335 y 336.

AEA, LXXV, 2002, 299, pp. 237 a 253 
En efecto, interesa puntualizar esto porque Aquiles arrastró en varias ocasiones el cadáver de Héctor en los Cantos XXII y XXIV de la Ilíada, pero mientras que en este último lo hace en el campamento aqueo, en torno al cadáver de Patroclo, ensañándose en su venganza, en el primero esto sucede ante los muros de Troya, después de matar al héroe, lo que está claramente expresado en el cuadro, que sigue fielmente el texto literario: «Dijo [Aquiles], e imaginaba ignominias contra el divino Héctor. / Le taladró por detrás los tendones de ambos pies / desde el tobillo al talón, enhebró correas de bovina piel / que ató a la caja del carro y dejó que la cabeza arrastrara. / Montó en la caja del carro, recogió la ilustre armadura, / los fustigó para arrearlos, y los dos de grado echaron a volar. / Gran polvareda se levantó del cadáver arrastrado; los cabellos / oscuros se esparcían, y la cabeza entera en el polvo / yacía, antes encantadora. Zeus entonces a sus enemigos / había concedido que lo ultrajaran en su propia patria» ${ }^{45}$. Así, el momento representado por Schmitz en su cuadro es el que nos muestra a Aquiles subido ya a su carro, junto a su auriga que fustiga a los caballos que se encabritan para echar a correr, llevando atado detrás al cadáver desnudo de Héctor, la cabeza en el polvo, despojado de su armadura, aquella que a su vez le había arrebatado a Patroclo tras matarlo, y que eran en realidad las armas de Aquiles, lo que se representa en el cuadro por medio del yelmo que éste lleva como trofeo en lo alto de su lanza; el tiro del carro es una biga, respondiendo al texto homérico, no así la batalla que se desarrolla entre esta escena y las murallas de Troya más al fondo, ya que el duelo entre ambos campeones se produjo en solitario, pero sí vemos las puertas Esceas, reproducidas claramente a la derecha del cuadro, donde Héctor esperó el ataque de Aquiles, y en lo alto de las murallas personajes masculinos y femeninos con gestos doloridos y desesperados representan a los familiares de Héctor que contemplaban desde allí impotentes y desesperados la trágica muerte del héroe y su cruel destino posterior, escenas que se desarrollan en el texto a continuación de los versos arriba reproducidos, en que Aquiles arrastra a Héctor atado a su carro, hasta el final de ese Canto XXII.

Nos llama la atención el vigor de la composición de esta obra, su dinamismo contenido, la tensión que subyace en el grupo principal, su calidad técnica y su frescura para estar realizada por un anciano de más de noventa años en 1881, año en que se halla firmada y fechada. Estaríamos tentados a pensar que hubiese sido realizada por el artista con bastante anterioridad a esa fecha y que la guardara desde entonces sin firma ni fecha, datos que añadió al cuadro en el momento de regalarlo a la Academia de San Fernando. El escorzo del cadáver de Héctor es de destacar por su belleza, con recuerdos de la buena pintura del siglo xvir; la figura de Aquiles, bien plantada sobre el carro, transmite fuerza, dinamismo, decisión; y los caballos están muy bien concebidos, tanto en su ejecución como en su postura de arranque encabritado. Todo ello sostenido por un dibujo de calidad y sentido en la concepción de los volúmenes. La obra resulta algo sorprendente para ser de un pintor desconocido. Su estilo responde a la formación neoclásica que recibiría, a juzgar por su edad, en la primera década del siglo xIX; pero, a pesar de su indudable neoclasicismo, tiene recuerdos en los fondos de la pintura española de los siglos XVI y XVII. Cuadro, por tanto, de un neoclasicismo muy «sui generis»que, como decimos, bien pudo ser pintado con anterioridad a la fecha de 1881, en que se halla firmado,

Y, por último, conocemos que también abordó asuntos de la Ilíada Vicente Jimeno Carra (Madrid, 1796-Madrid, 1857), discípulo de Maella y, especialmente, de Vicente López, quien fue pensionado en Roma para seguir allí sus estudios en 1819, donde buscó iniciarse en el neoclasicismo de David, prolongando su estancia en la capital italiana más allá de 1825; vuelto a España, regresó otra vez a Roma en 1846, donde pintó, por encargo del conde de Isla Fernández y el conde de Tepa algunos cuadros de temática del mundo de la antigüedad clási-

${ }^{45}$ Homero: Op. cit. nota 9, pp. 550 y 551 (versos 395 a 404). 
ca, y entre ellos, concretamente, para este último, Dos asuntos de la Ilíada, citados así por Ossorio y Bernard sin indicarnos cuáles fuesen sus argumentos ${ }^{46}$. Este interés por el mundo homérico se manifiesta también en su labor como dibujante, realizando las láminas de la Ilía$d a$ al contorno, que grabó al aguafuerte, así como el cuadro titulado Homero contando su vida ${ }^{47}$.

Pues bien, si los temas de la Ilíada se reducen a unos pocos a lo largo del siglo, como hemos visto (lo que no quiere decir que aparezca alguno más, pero desde luego no muchos), los asuntos sobre el otro poema homérico, la Odisea, se nos muestran aún más escasos en nuestra pintura decimonónica. De hecho, sólo hemos recogido tres cuadros referentes a dicha obra y ninguno de ellos realizado por un pintor de gran talla del siglo, sino por artistas destacados dentro de la media del panorama pictórico de la centuria.

Colocándolos por la cronología que discurre en la obra, el primero que corresponde ser citado es el de Ulises atraído por las sirenas, de Inocencio García Asarta (Gastiáin, Navarra, 1861-Bilbao, 1921), pintor formado en la Academia de Bellas Artes de Vitoria y con estancias en Roma y París ${ }^{48}$. Conocemos el título del cuadro porque éste fue presentado por su autor a la Exposición Nacional de Bellas Artes de 1904, como así consta en su catálogo, donde, por las medidas que allí se nos proporcionan de $0,38 \times 0,53 \mathrm{~ms}$., más que cuadro diríamos que se trata de un cuadrito ${ }^{49}$. Pero interesante, pues a pesar de que el asunto pueda en principio parecer muy manido, es «rara avis» en la pintura española. En efecto, se conocen obras de pintores europeos de la época sobre el tema, pero en España es la única de que, al menos nosotros, tenemos noticia. Aunque hoy día nos es desconocida, ignorando cual sea su paradero, sin embargo, la claridad del título no ofrece la más mínima duda respecto a su asunto, fácilmente identificable en la Odisea, pues se trata de uno de los episodios más famosos de la misma, ya interpretado incluso en los vasos griegos y en los mosaicos romanos en la Antigüedad. E indudablemente, al igual que los artistas que entonces lo representaron, el cuadrito de García Asarta se inspiraría en los mismos versos del Canto XII de la Odisea: «Uno a uno a mis hombres con ellos [trozos de cera] tapé los oídos / y, a su vez, a la nave me ataron de piernas y manos / en el mástil, derecho, con fuertes maromas y, luego, / a azotar con los remos volvieron el mar espumante. / Ya distaba la costa no más que el alcance de un grito / y la nave crucera volaba, mas bien percibieron / las Sirenas su paso y alzaron su canto sonoro: / [viene a continuación el canto y luego sigue] / Tal decían exhalando dulcísima voz y en mi pecho / yo anhelaba escucharlas. Frunciendo mis cejas mandaba / a mis hombres soltar mi atadura; bogaban doblados / contra el remo y en pie Perimedes y Euríloco, echando / sobre mí nuevas cuerdas, forzaban cruelmente sus nudos» ${ }^{50}$. Es decir, la obra de García Asarta representaría, tomando la idea principal del texto, a Ulises atado al mástil de la nave, a sus compañeros remando en silencio y quizá algún personaje en pie aludiendo a Perimedes y Euríloco, viendose también, de alguna forma, las sirenas. Este momento, idea central del pasaje, es el representado generalmente por casi todos los artistas que abordaron este famoso fragmento de la Odisea desde la Antigüedad.

Y, por último, mencionaremos dos cuadros de diferentes autores que emprendieron el mismo asunto de la Odisea con el común título de Ulises reconocido por su nodriza; uno de An-

\footnotetext{
${ }^{46}$ Ossorio y Bernard, M.: Op. Cit. nota 15, p. 350.

47 Ibidem.

48 Para más información sobre Inocencio García Asarta véase: Urricelqui, I. J.: «Revisión de un lienzo de Inocencio García Asarta», Príncipe de Viana, núm. 222, Pamplona, enero-abril de 2001, p. 57.

${ }^{49}$ Catálogo de la Exposición Nacional de Bellas Artes de 1904, Edición Oficial, Casa Editorial Mateu, Madrid, 1904, p. 10, núm. 95.

50 Homero: Odisea, (introducción de Manuel Fernández-Galiano, traducción de José Manuel Pavón), Ed. Gredos, Madrid, 1982, pp. 290 y 291 (versos 177 a 196).
} 
tonio Gómez y Cros (Valencia, 1808-Madrid, 1863) y el otro de Calixto Ortega (?). El de Gómez y Cros, que fue conocido pintor de historia, discípulo y seguidor de Vicente López, cuyo estilo tradicional de escuela valenciana con tintes románticos nos es perfectamente conocido, fue premiado en las sesiones prácticas del Liceo Artístico y Literario Español de Madrid, sociedad ejemplarmente romántica de la que fue uno de sus más entusiastas socios ${ }^{51}$. El de Ortega, grabador en madera y pintor, activo en la primera mitad del siglo xix, del que sólo sabemos que fue discípulo de la Academia de San Fernando, fue también pintado en las sesiones prácticas del citado Liceo, sociedad a la que perteneció desde sus orígenes ${ }^{52}$.

El hecho de que ambos cuadros fuesen pintados en las sesiones prácticas de carácter competitivo del Liceo Artístico y Literario Español por dos activos socios del mismo, y que Ossorio y Bernard, que es quien los cita, les de exactamente el mismo título, nos hace suponer que ambas obras fuesen pintadas por estos dos artistas en la misma sesión práctica, en competencia entre ellos y quizá con algún otro pintor, sobre un tema impuesto para dicha sesión, en este caso el de Ulises reconocido por su nodriza. De ahí el mismo título recogido para ambas obras por Ossorio y Bernard y que las cite como realizadas en dichas sesiones prácticas. Así, cuando Ossorio y Bernard se refiere a la obra de Ortega calificándola como «su cuadrito», pensamos que esto sea también aplicable a la obra de Gómez y Cros, ya que en dichas sesiones prácticas, realizadas cara al público y en un tiempo determinado, no podrían pintarse cuadros de grandes o medianas dimensiones, sino más bien de pequeño formato.

En cuanto al asunto representado por ambos pintores correspondería al Canto XIX de la Odisea, cuando Ulises disfrazado de mendigo cuenta a Penélope, ante la insistencia de ésta, la inventada historia de su procedencia de noble linaje cretense caído en la ruina y la mendicidad y que dio hospedaje, en tiempos mejores, a su marido cuando iba camino de Troya, anunciándole, además que Ulises no había muerto y que estaba de regreso a su casa. Ante esto, Penélope manda que le laven y le preparen un lecho, pero Ulises se niega a que sean las infieles criadas quienes lo hagan, mandando entonces Penélope a la anciana Euriclea, nodriza de Ulises, que sea ella quien lo lave; ésta nota previamente el parecido del mendigo que tiene que lavar con el de Ulises, pero no lo reconoce ante la sagaz respuesta que le da el laertíada: «Así dijo; la anciana cogió la brillante caldera / que servía al lavatorio, vertió cantidad de agua fría / y añadió la caliente después, mas Ulises en tanto, / dando espalda al hogar, se sentó prestamente en la sombra, / pues de pronto pensó que la anciana iba a verle en la pierna / una gran cicatriz con que todo sería descubierto. / Ella vino y, lavando a su dueño, notóle la mella / que marcó un jabalí con sus blancos colmillos un día / que al Parnaso él subió con Autólico, abuelo materno / que era suyo, y los hijos de éste... / [se narra a continuación la historia de como le produjo la herida el jabalí, y sigue la escena luego]. / Al frotar con sus manos notóle esta mella la anciana, / conocióla en el tacto y soltó conmovida la pierna, / que, cayendo de golpe en la tina y sonando en el bronce, / la volcó hacia delante y el agua vertióse en la tierra. / La alegría y el dolor la tomaron a un tiempo. Sus ojos / se llenaron de llanto, la voz se perdió en su garganta, / mas a Ulises, al cabo, cogió del mentón y le dijo: / <Cierto tú eres Ulises, mi niño querido, y no supe / conocerte yo misma hasta haberte palpado las carnes, / ¡tú, mi dueño!> (...)» ${ }^{53}$. Este es el texto que propondría el jurado para la sesión práctica del Liceo en que se pintaron estos cuadritos y, aunque habría, sin duda, variaciones entre uno y otro, estamos seguros que ambos representarían como escena central la idea básica que subyace en el texto, o sea, a Ulises sentado junto al hogar teniendo a Euriclea agachada delante lavándole los pies en la tina de bron-

51 Ossorio y Bernard, M.: Op. Cit. nota 15, pp. 296 y 297.

52 Ibidem, p. 496.

${ }^{53}$ Homero: Op. Cit. nota 50, pp. 413, 414 (versos 386 a 395) y 416 (versos 467 a 476 ).

AEA, LXXV, 2002, 299, pp. 237 a 253 
ce, bien con un gesto de sorpresa ante su descubrimiento, bien cogiéndole el mentón a Ulises como asimismo indica el texto. También sabemos, gracias a Ossorio y Bernard ${ }^{54}$, que el premio se lo llevó Gómez y Cros, sin duda mejor pintor que Ortega, más dedicado éste profesionalmente a las labores de grabador.

Vemos, pues, que los asuntos homéricos fueron, en general poco abordados por nuestros pintores, siendo, fundamentalmente, los que a esta temática dedicaron sus pinceles, artistas neoclásicos, como Aparicio, José de Madrazo, Verdú, Schmitz, Jimeno Carra o el joven Federico de Madrazo formándose con su padre; o bien pintores que, aunque desarrollaron su labor en la etapa romántica, se pueden considerar dentro, en mayor o menor grado, de la estela neoclásica, como Tejeo, Gómez y Cros u Ortega. Y casi todos ellos realizaron preferentemente asuntos de la Ilíada, cuyo carácter heroico se adecuaba más al espíritu neoclásico. García Asarta se sale de este esquema, ya que su pintura se desarrolla a finales del siglo XIX y principios del xx, y su asunto de Ulises atraído por las sirenas parecería encajar más en otras corrientes finiseculares, quizá dentro de las sugerencias del simbolismo o de Alma-Tadema y del movimiento «clasicista» inglés en general.

${ }^{54}$ Ossorio y Bernard, M.; Op. Cit. nota 15, p. 297. 